\title{
Mídias na Educação: gestão eficiente para uma prática pedagógica qualificada em EaD
}

Rafael Mateus Teixeira Almeida, aluno do curso de Administração da Universidade Luterana do Brasil - ULBRA, rafaelalmeida@globo.com

Mary Lúcia Pedroso Konrath, Pedagoga, Especialista em Informática na Educação, Mestre em Educação e Doutoranda do Programa de Pós-Graduação em Informática na Educação PPGIE/UFRGS, marykonrath@globo.com

Cleuza Maria Maximino Alonso, Doutora em Informática na Educação - PPGIE/UFRGS, professora e coordenadora da UAB e coordenadora do curso de especialização em Mídias na Educação pela Universidade Federal de Santa Maria, alonsoc@terra.com.br

Roseclea Medina, Doutora em Informática na na Educação - PPGIE/UFRGS, professora e vicecoordenadora do curso de especialização em Mídias na Educação pela Universidade Federal de

Santa Maria, roseclea.medina@gmail.com

Resumo. Este artigo tem como objetivo propor possíveis encaminhamentos para o desenvolvimento de uma prática pedagógica eficiente em cursos $\mathrm{EaD}$, levando em consideração fatores relevantes ao processo de gestão que devem ser considerados no planejamento destas arquiteturas pedagógicas, para que se tenha qualidade e êxito nesta modalidade de ensino. Como base para desenvolvimento deste artigo, serão apresentadas a experiências teórico-práticas relacionadas ao curso de Especialização Mídias na Educação oferecido pelo Ministério da Educação, em parceira com a Universidade Federal de Santa Maria/RS.

Palavras-chave: arquitetura pedagógica, gestão eficiente, planejamento, $\mathrm{EaD}$

Abstract. This paper aims to propose possible routes for the development of an efficient teaching courses EAD, taking into account factors relevant to the management process that must be considered in planning these architectures teaching, to have quality and success in this type of education. As a basis for development of this paper shall be made to theoretical and practical experiences related to the specialization course in Media Education, offered by the Ministry of Education, in partnership with the Federal University of Santa Maria in Rio Grande do Sul

Keywords. teaching architecture, efficient management, planning, Distance education

\section{Introdução}

Estamos diante de inovações tecnológicas que permitem inovar no processo de ensinoaprendizagem re-significando os papéis dos atores envolvidos (alunos, tutores e professores) e da prática pedagógica em $\mathrm{EaD}$, tornando-a mais efetiva. 
Desta forma, é pertinente reiterar a importância do planejamento prévio da arquitetura pedagógica do curso, na qual deve-se evidenciar a concepção pedagógica que será colocada em prática e os processos de gestão voltados para a qualidade do curso, o que certamente poderá facilitar e qualificar a prática pedagógica desenvolvida no mesmo.

Segundo Castells (1999) estamos vivendo efetivamente em uma sociedade informacional, onde os indivíduos precisam se adaptar as inovações tecnológicas que os cercam, através de uma devida apropriação destes recursos. A interação fez com que se rompessem barreiras e tornou-se efetivamente um meio global de comunicação, principalmente pela rede de informações (Internet), na qual inevitavelmente todos, de alguma forma passaram a fazer parte.

Neste sentido o processo de aprendizagem, na modalidade a distância poderá abreviar a constante busca pelo conhecimento, através de cursos que além de uma boa proposta, tenham elementos que possibilitem gerir de forma adequada os processos envolvidos no curso, entre eles o plano de curso e seus objetivos, processos e mecanismos de apoio a aprendizagem, tecnologias utilizadas, procedimentos formais acadêmicos, avaliação, estratégias e práticas, assim como as relações que cada envolvido (aluno, tutor e professor) estabelece com os outros, com os conteúdos e com a avaliação.

Este artigo apresenta o que é a EaD e descreve os elementos básicos de uma arquitetura pedagógica. No capítulo seguinte, enumera alguns elementos importantes para uma prática eficiente em $\mathrm{EaD}$ no tocante a questão de Gestão, trazendo a tona os temas planejamento, gestão da aprendizagem, gestão financeira e de pessoal, gestão do conhecimento e gestão como eficiência. E por fim, descreve as experiências teórico-práticas relacionadas ao curso de Especialização Mídias na Educação.

\section{EaD, arquiteturas pedagógicas e seus elementos}

A educação a distância (EaD) é "[...] o aprendizado planejado que ocorre normalmente em um lugar diferente do local de ensino, exigindo técnicas especiais de criação do curso e de instrução, comunicação por meio de várias tecnologias e disposições organizacionais e administrativas especiais" (MOORE e KEARSLEY, 2007)

De um modo geral, pode-se dizer que sistemas de EAD apresentam de acordo com Bof (2002):

1.Estrutura/mecanismos de planejamento e preparação/disponibilização de materiais instrucionais (sejam eles escritos, audiovisuais, ou on-line);

2. Estrutura/mecanismos para a provisão de serviços de apoio à aprendizagem aos cursistas (Tutoria, serviços de comunicação, momentos presencias);

3. Serviços de Comunicação que possibilitam o acesso do cursista às informações necessárias ao desenvolvimento de suas atividades no curso; 
4. Sistemática de avaliação definida e operacional;

5. Estrutura física, tecnológica e de pessoal compatível com a abrangência da atuação da instituição e o tipo de desenho instrucional dos cursos oferecidos;

6. Estrutura e mecanismos de monitoramento e avaliação do sistema.

Todos os componentes envolvidos nessa dinâmica formam a estrutura operacional, na qual todos os elementos precisam funcionar de forma integrada para que se obtenha sucesso com estes cursos.

Embora seja sabido que não há um modelo único de EaD, pois os cursos podem apresentar diferentes concepções, formatos, com recursos educacionais e tecnológicos diversos, os elementos que organizam um sistema EaD servem como base para sua estruturação e gestão.

Desta forma, muitas variáveis estão envolvidas num sistema $\mathrm{EaD}$ e por isso não podemos subestimar sua complexa dinâmica, que exige que sejam pensados, praticados e avaliados todos os elementos de forma individual e a partir de seu relacionamento com o todo. Isto pode garantir que se tenha qualidade, eficiência e eficácia em todos os processos e no curso como um todo.

Arquiteturas pedagógicas (AP) são definidas neste contexto como

"[...] um sistema de premissas teóricas que representa, explica e orienta a forma como se aborda o currículo e que se concretiza nas práticas pedagógicas e nas interações professor-aluno-objeto de estudo/conhecimento [...] constituída por um gama de elementos organizacionais, instrucionais, metodológicos e tecnológicos, os quais mantêm uma inter-relação". (BEHAR, 2008, p.4 )

Os elementos ${ }^{1}$ organizacionais, instrucionais, metodológicos e tecnológicos envolvem fatores que precisam ser levados em consideração. Desta forma, para a construção de uma arquitetura pedagógica que permita a gestão eficiente em programas educacionais na modalidade $\mathrm{EaD}$, é preciso que seja dada atenção a estes fatores que fazem parte dos elementos de uma AP. Estes fatores envolvem desde o planejamento até a prática pedagógica desenvolvida nos cursos, tais como: (a) às necessidades para criação do programa/curso, (b) objetivos educacionais, (c) desenho instrucional, etapas e atividades, (d) equipe do curso e definição de suas atribuições de acordo com as funções desempenhadas, (e) mecanismos de apoio à aprendizagem no que tange as interações e como elas se aplicam na prática, (f) tecnologias a serem utilizadas para apoiar o processo de ensinoaprendizagem, $(\mathrm{g})$ processos de avaliação, $(\mathrm{h})$ os procedimentos formais acadêmicos e os co-relacionamentos do funcionamento do sistema como um todo.

\footnotetext{
${ }^{1}$ Para saber mais sobre o conceito de arquiteturas pedagógicas e/ou sobre seus elementos acesse o objeto de aprendizagem ARQUEAD - Arquitetando a Educação a Distância, disponível através do endereço http://homer.nuted.edu.ufrgs.br/arquead/
} 


\section{Gestão: elementos importantes para uma prática eficiente em EaD}

A gestão é fator fundamental na $\mathrm{EaD}$, porque é através dela que se organizam e gerenciam os sistemas de cursos nesta modalidade, garantindo que sejam alcançados os objetivos educacionais previstos pela proposta educacional do curso.

Segundo Oliveira (2004, p. 324) o conceito de gestão pode ser definido como:

Processo em que os indicadores, parâmetros e critérios de avaliação, bem como a realidade atual das atividades, ficam disponíveis para acompanhamento e possível intervenção de todos os demais envolvidos, de forma direta ou indireta, nas atividades consideradas.

Neste sentido, retoma-se a importância do planejamento, operacionalização para funcionamento eficiente do sistema, desenvolvimento e análise dos fatores e processos relacionados através de monitoramento e avaliação, assim como mecanismos que possibilitem a identificação de problemas, de modo que estratégias possam ser definidas para a sua imediata resolução.

O planejamento é o primeiro passo para ter êxito na gestão de um sistema e quanto mais detalhado e organizado ele for, menos falhas poderão ocorrer em sua operacionalização.

Segundo STEINER (1969) o planejamento é um processo que envolve cinco dimensões: (1) assunto abordado, (2) elementos do planejamento (propósito, objetivo, estratégias, políticas, recursos, orçamentos, normas e procedimentos, entre outros), (3) tempo de planejamento, prática, acompanhamento e avaliação, (4) organização das áreas, dos profissionais envolvidos e de suas atribuições no planejamento, implantação, desenvolvimento, acompanhamento e avaliação e (5) viabilidade do projeto.

A partir de Oliveira (2004) adequou-se os princípios gerais de planejamento para uma instituição educacional, na busca que os resultados de sua operacionalização sejam alcançados: (1) organizar os objetivos e o curso de acordo com a proposta e concepção pedagógica do curso, (2) organizar e definir como será a estrutura (recursos, pessoal, acompanhamento e avaliação), (3) definir parâmetros e critérios de avaliação para os processos pensados e praticados pelo curso como forma de intervir para buscar eficácia e (4) intervir a partir dos parâmetros definidos de forma a maximizar os resultados e minimizar as deficiências do mesmo.

Neste sentido, os gestores de sistemas de cursos EaD precisam assumir e desenvolver competências, habilidades e atitudes para o gerenciamento, além de criar novas possibilidades para tornar eficiente todos os processos envolvidos na gestão nesta modalidade de ensino.

A gestão em EaD precisa ser dinâmica, flexível, adaptável pois seu objeto de estudo e intervenção é um organismo vivo, ou seja, um campo de ações e interações humanas na qual os sujeitos podem participar de sua própria criação. Fazem parte deste organismo 
como subsistemas a estrutura física (pólos e sede), pessoal (alunos, tutores, professores especialistas e formadores), a instituição de ensino superior, etc.

Sartori (2005), divide a Gestão em três grupos: (1) gestão da aprendizagem, (2) gestão financeira e de pessoas, (3) gestão do conhecimento.

A gestão da aprendizagem está diretamente associada às questões pedagógicas, exigindo planejamento, organização, controle, liderança e coordenação das equipes e das atividades necessárias para ações de seu desenvolvimento. Trabalha diretamente com os sistemas de apoio à aprendizagem e avaliação, além de envolver cada uma das ações que devem ser desenvolvidas para que estas ocorram eficientemente. Assim fazem parte desta:

- o desenho pedagógico

- produção do material didático

- construção de planos e cronogramas

- etapas e atividades

- mecanismos gerenciais para auxiliar (acompanhamento e avaliação):

o o coordenador no acompanhamento do trabalho do professor

- o professor no acompanhamento do trabalho do tutor e

- o professor e o tutor no acompanhamento do processo de estudo dos alunos

- mecanismos de comunicação com atendimento eficiente, respostas precisas e em tempo hábil

- plantões pedagógicos (presencial, telefone, chat)

- definição clara e conhecimento por todos do sistema de avaliação (indicadores e instrumentos)

- formação (capacitação) e acompanhamento dos envolvidos no processo de EaD

A gestão financeira envolve o levantamento de custos e sua análise, captação e gestão de recursos, contratação, remuneração e investimento em capacitação de pessoal, ou seja, diz respeito a todas as tarefas financeiras e administrativas necessárias a implantação e execução do programa de EaD.

A gestão do conhecimento refere-se à disponibilidade da informação, a qual precisa estar acessível sempre que necessário e a todos. É o conjunto de processos que governa a criação, a disseminação e a utilização do conhecimento no âmbito das instituições de ensino. Envolve várias maneiras de captar e distribuir o aprendizado cumulativo, construído a partir dos saberes individuais e coletivos.

Quando buscamos gerir algo, precisa ser levado em consideração, como eixo principal, o objetivo pretendido com a proposta em si. Desta forma é relevante ser levantado todos os procedimentos necessários para que se alcance a eficiência ao final do processo. Sabemos que nada é absoluto, mas é preciso indicar possíveis caminhos para o desenvolvimento do projeto.

Neste sentido, ao longo deste artigo são mencionadas algumas etapas importantes, como: análise, planejamento, desenvolvimento e agentes principais de cursos de EaD. Assim estas etapas precisam seguir uma seqüência pré-estabelecida no planejamento inicial, onde serão delineados os papéis e atribuições de cada um no curso. 
A partir deste desenho estrutural é possível, em caso de situações adversas indicar possíveis caminhos para a solução dos problemas, como também, em situações onde se obteve êxito registrá-las, no sentido de ao final do processo indicá-las para uma próxima edição de curso.

Através do efetivo retorno dos alunos e tutores é possível conhecer as adversidades, o que fornece um aporte palpável para os coordenadores e, estes por sua vez, podem tomar as medidas necessárias para solucionar situações problemas que possam surgir ao longo do curso tomando medidas para evitá-las na mesma ou em edições posteriores.

Com base em (MOORE e KEARSLEY, 2007) é possível utilizar como indicadores para avaliação da eficiência e eficácia das arquiteturas pedagógicas de um curso itens relacionados ao planejamento e avaliação, tais como:

Indicadores de eficiência (planejamento)

- características do aluno, incluindo saber como estudar a distancia

- experiência do professor e entendimento dos alunos de educação a distancia

- qualidade das aptidões para elaboração e produção do curso

- custo de criação e produção do curso

- tecnologias escolhidas

- acessibilidade dos serviços de apoio

- frequiência e qualidade dos dados de avaliação

- investimento financeiro

Indicadores de eficácia (avaliação)

- índices de satisfação do aluno

- resultados apresentados pelo aluno

- índice de finalização do curso

- número total de matrículas

- avaliações da qualidade

- resultados da certificação

- mensalidades escolares e outras receitas

- reputação e rotatividade das pessoas envolvidas no processo

A complexidade dos elementos e sua interação nos sistemas de $\mathrm{EaD}$, nos impõe que cada vez mais seja buscado um gerenciamento eficiente dos processos envolvidos. A eficiência de um programa pode ser avaliada a partir de indicadores que demonstrem o êxito nos seus propósitos. Deve ser levada em conta a gestão da aprendizagem, financeira e de pessoal e do conhecimento. Não basta ter uma boa proposta e planejamento e não saber lidar com os problemas ocorridos ao longo de seu desenvolvimento, pois como um organismo vivo ele precisa estar em perfeita sincronia.

Percebe-se também, a necessidade do trabalho adequado e diferenciado da equipe gestora da instituição, juntamente com o seu grupo de trabalho (professores, tutores e alunos), assim como apropriado a realidade dos seus alunos. 
A partir dos elementos elencados e dos indicadores buscou-se olhar para as experiências teórico-práticas relacionadas ao curso de Especialização Mídias na Educação, como forma de verificar que práticas de gestão têm sido eficientes.

\section{Curso Mídias na Educação: gestão e práticas eficientes}

O programa é desenvolvido pela Secretaria de Educação a Distância (Seed), em parceria com secretarias de educação e universidades públicas - responsáveis pela produção, oferta e certificação dos módulos e pela seleção e capacitação de tutores.

Entre os objetivos do programa estão: destacar as linguagens de comunicação mais adequadas aos processos de ensino e aprendizagem; incorporar programas da Seed (TV Escola, Proinfo, Rádio Escola, Rived), das instituições de ensino superior e das secretarias estaduais e municipais de educação no projeto político-pedagógico da escola e desenvolver estratégias de autoria e de formação do leitor crítico nas diferentes mídias.

O curso Mídias na Educação é um curso de especialização oferecido pelo Ministério da Educação e Cultura - MEC, em parceria com diversas universidades. Aqui serão apresentadas as experiências teórico-práticas relacionadas ao programa no âmbito da Universidade Federal de Santa Maria (UFSM) no Rio Grande do Sul.

O curso tem estrutura modular, que visa proporcionar formação continuada para o uso pedagógico das diferentes tecnologias da informação e da comunicação - TV e vídeo, informática, rádio e impresso.O público-alvo prioritário são os professores da educação básica. A estrutura de ciclos e módulos permite aos alunos começarem a sua trajetória de aprendizagem no ciclo introdutório e continuarem o seu processo de aprendizagem, nos ciclos: intermediário e avançado.

Esta estrutura, posta em prática na UFSM leva em conta as devidas adequações dos conteúdos em módulos que evoluem e aumentam o nível de exigência. Isto faz com que os alunos reflitam sobre o processo, na medida em que estes desenvolvem uma efetiva interação com a turma, contribuindo assim, para a sua evolução pessoal, no sentido da utilização das ferramentas midiáticas.

O curso está em sua $3^{\mathrm{a}}$ edição do ciclo básico, $2^{\mathrm{a}}$ edição do Intermediário e $1^{\mathrm{a}}$ edição do Avançado e conta ao todo com aproximadamente 400 alunos.

Estes alunos moram em diversos estados situados próximos a Sede que fica em Santa Maria. Para os encontros presenciais há pólos que são utilizados para a capacitação e avaliação dos alunos, entre eles: Santa Maria, Santa Cruz, Bagé, Bento Gonçalves e Três de Maio.

O curso trabalha as mídias Informática, TV e vídeo, Rádio, Impressa e ao final a integração destas, a partir da Gestão Integrada de Mídias na Educação.

No módulo gestão integrada de mídias, ao final do ciclo introdutório são retomados os recursos que foram trabalhados ao longo do curso e o aluno é desafiado a buscar 
mecanismos, para uma efetiva aplicação das mídias no cotidiano escolar, através de um prévio planejamento e análise das ferramentas disponíveis na instituição de ensino. Assim como também, é incentivado a buscar recursos, através programas dos governos municipais (Nota é Minha) ou federais, que possam contribuir com recursos financeiros para os projetos de sua instituição.

A partir deste trabalho de inclusão das mídias no espaço escolar, os alunos passam a ter um real interesse em participar das atividades propostas se apropriando das mídias e melhorando o convívio em sala de aula.

Os professores do curso conseguem planejar gradativamente ao longo do curso, projetos nos quais as atividades buscam integrar o processo de ensino-aprendizagem com a utilização de ferramentas de interação, como a TV, vídeo e o rádio. Em um segundo momento este planejamento acaba sendo colocado em prática e tem tornando conforme relato dos próprios professores, o ambiente escolar mais interativo e instigante aos alunos.

A exemplo disso, temos o projeto das alunas de Venâncio Aires que através do projeto Nas Ondas do Rádio, publicado através de reportagem na Revista Escola, implementou um programa com reportagens e entrevistas ao vivo. O programa intitulado Nas Ondas da Educação, que vai ao ar na rádio comercial Venâncio Aires 910 AM, em parceria com quatro escolas da rede municipal de Venâncio Aires. O objetivo do projeto foi o de melhorar o desempenho escolar dos alunos da EJA (Educação de Jovens e Adultos) trabalhando os conteúdos escolares através do uso da mídia rádio.

Os desafios propostos pelo curso, aos professores cursistas tornam a sua prática mais próxima da convivência tecnológica, onde as mídias fazem parte efetiva deste contexto de ensino-aprendizagem.

Entre os problemas que surgiram no curso e foram resolvidos tem-se: (a) trabalhar o novo papel do aluno virtual e suas responsabilidades (auto-organização de tempo e estudo), (b) capacitar os alunos a apropriarem da dinâmica da $\mathrm{EaD}$ e do ambiente virtual de aprendizagem utilizado, (c) criar os elos afetivos entre alunos e tutores através dos encontros presenciais e manter estes durante o curso através do ambiente virtual de aprendizagem, (d) fazer com que todos os tutores e professores envolvidos conseguissem manter a presença na comunicação, como instigador desta comunicação, opinando, informando, estabelecendo e mantendo contato a distância, convidando alunos para participar e corrigindo.

Seguem algumas das práticas eficientes de gestão do curso nesta universidade:

- processos de capacitação de pessoal (professores, tutores e alunos)

- organização e definição do cronograma de acordo com a proposta do curso, ciclos, módulos e etapas do curso e comprometimento necessário com o mesmo

- definição dos atores envolvidos e de suas atribuições (construção do manual do aluno e do tutor)

- escolha e manutenção do ambiente virtual de aprendizagem 
- disponibilização dos materiais referentes a organização do curso, sua proposta e outros documentos no ambiente virtual de aprendizagem selecionado para o curso

- definição dos mecanismos gerenciais de acompanhamento do trabalho dos tutores e dos tutores no processo dos alunos.

- estabelecimento de comunicação recíproca e atendimento eficiente (MEC, coordenador do curso, professores, tutores e alunos), através de respostas claras e em tempo hábil.

- organização de relatórios sobre o curso (andamento, problemas, etc.) reportados para as coordenações (curso na instituição e do programa no MEC).

- sistema de avaliação claramente definido e conhecido por todos seguindo os critérios da universidade. Proposição de indicadores e instrumentos que possibilitem o desenvolvimento desta avaliação na prática e clareza na definição dos agentes encarregados desse processo.

- monitoramento e a avaliação das equipes pelo coordenador e coordenador de tutoria

- gestão dos recursos financeiros (deslocamentos encontros presenciais, manutenção de equipamentos para o funcionamento do curso, etc.).

- gestão dos processos acadêmicos (matrícula, recebimento de certificação).

- produção e distribuição de materiais (CD com os respectivos módulos a serem trabalhados)

- divulgação do curso através das mídias (portal, jornal, etc) e seleção dos professores, tutores e alunos.

Não se pode deixar de salientar, a necessidade de que todo este sistema teve e tem de funcionar como um todo interoperante, partes que devem funcionar articuladamente mantendo o organismo vivo. Os problemas sempre vão existir, porém não se pode deixar que as partes comprometam o todo e é nesse sentido que se buscou trazer elementos importantes da gestão e práticas eficientes adotadas pelo curso.

\section{Considerações finais}

Diante desse contexto é possível observar a complexidade da estrutura e dos processos envolvidos na EaD. Além disso, o quanto é preciso que a equipe gestora da instituição se preocupe com o aspecto formativo e qualitativo, assim como na busca por práticas eficientes de gestão que detectem e solucionem os problemas encontrados no planejamento, desenvolvimento e operacionalização dos cursos.

Neste sentido, pensa-se na importância de contar com uma equipe de profissionais especialistas de diferentes áreas que atuem de forma cooperativa. Esta equipe gestora precisa acompanhar e avaliar as atividades pedagógicas, administrativas, financeiras e de suporte técnico garantindo o êxito e a qualidade do curso e de suas interações.

\section{Referências Bibliográficas}

BEHAR, Patrícia Alejandra. Arquiteturas pedagógicas. Porto Alegre: UFRGS, 2008.

Disponível em: <http://homer.nuted.edu.ufrgs.br/arquead/aps.html> 


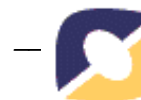

BOF, Alvana Maria. Gestão de Sistemas de Educação a Distância. 2002 In: Gestão de programas de EAD. Disponível em: < http://www.tvebrasil.com.br/SALTO/boletins2002/ead/eadtxt2b.htm>

CASTELLS, Manuel. A sociedade em rede. São Paulo, Paz e Terra S.A., 1999.

MOORE, Michael; KEARSLEY, Greg. Educação a Distancia - Uma visão Integrada. São Paulo: Thomson Learning, 2007.

OLIVEIRA, Djalma. Planejamento Estratégico. São Paulo, Atlas, 2004.

SARTORI, Adelaide Silveira. Educação superior à distância: gestão da aprendizagem e da produção de materiais didáticos impressos e on-line. Tubarão; Unisul, 2005.

STEINER, George A. Top managment planning. New York: Macmillan, 1969. 